\title{
Strength Estimation of Coke as Porous Material*
}

\section{By Kunihiko NISHIOKA** and Shuhei YOSHIDA**}

\section{Synopsis}

Research on the coke strength has recently been carried out treating the coke as a porous material and a new progress is made in the essential evaluation of coke strength. Previous researches have, however, discussed mainly the effects of porosity andlor distribution of pores on the strength and little has been studied on the inherent strength which affects the coke strength.

In this research, a sieve opening for strength index applied to the microstrength which evaluates the inherent strength was investigated. The micro-strength with a smaller sieve opening was found to be a reasonable index for the inherent strength of coke.

It was confirmed that the tensile strength is estimated by porosity and micro-strength. The JIS drum strength which is usually used in industrial plant is also estimated from the porosity and the microstrength through the tensile strength. The results show that the coke strength is determined by the strength of porous material which depends on its porosity and inherent strength.

\section{Introduction}

In the previous paper, ${ }^{1)}$ the dilatation of coal has been discussed. This is the basis for the analysis of coal particle bonding mechanism and the first step to understand the coking mechanism. This paper discusses the factors determining the coke strength which is necessary for the analysis of the mechanism generating the strength.

A large number of studies have been reported concerning the coke strength which is one of the most important fields in the coke technology. Most of the studies are on the drum index currently used as a quality controlling index in plants and the results have been effectively applied for the improvements in production and utilization of coke. On the other hand, there are only a few reports which analyze the inherent strength and the basic research on the coke strength has been insufficient.

The previous researches are based on the idea that the coke strength depends mostly on cracks generated during carbonization and the coal properties such as coalification rank and fluidity. ${ }^{2-5)}$ Unfortunately, these studies have not yet yielded any quantitative conclusions with a theoretical explanation which can be generally applied. Studies are currently carried out, however, based on the concept that coke is a porous material. With this concept, the results of previous researches can yield a new development of the analysis of the coke strength. ${ }^{6-9}$ )

This research is based on the same concept. The inherent strength has not been properly discussed because of difficulties in the direct measurement of its strength. The authors have introduced the microstrength as an indirect index of inherent strength and analyzed the coke strength. Additionally, the correlation between the JIS drum index for production control and the tensile strength for research index was investigated.

\section{Test Procedures}

\section{Preparation of Coke Specimen}

Preparation of test specimen is an important subject for the research on strength. Especially for the coke strength, it is preferable to use a large number of specimens because of rather wide fluctuation of measured data. However, the production of large amounts of coke with a uniform quality is difficult. This can be overcome by the following procedure.

An electrically heated test oven of $450 \mathrm{~mm}$ width and $250 \mathrm{~kg}$ coal capacity is charged with a single kind of coal or blended coal shown in Table 1, and the coals with different bulk density are carbonized at various carbonization temperatures. With this procedure, a large amount of coke with macroscopically uniform quality can be produced from the same charging coal at several carbonization temperatures and with several porosity values. Then, the coke

Table 1. Properties of coals.

\begin{tabular}{l|cccccc}
\hline \multicolumn{1}{c|}{ Coal } & $\begin{array}{c}\text { Ash } \\
(\%, \text { d.b. })\end{array}$ & $\begin{array}{c}\text { Volatile matter } \\
\text { (\%, d.b.) }\end{array}$ & $\begin{array}{c}\text { Max. fluidity } \\
(\text { log, ddpm) }\end{array}$ & $\begin{array}{c}\text { Total reactives } \\
(\%)\end{array}$ & $\begin{array}{c}\text { Mean reflectance } \\
(\%)\end{array}$ & $\begin{array}{c}\text { Blending ratio } \\
(\%)\end{array}$ \\
\hline Cerro & 9.2 & 18.1 & 1.10 & 88.4 & 1.53 & 15 \\
Balmer & 9.7 & 20.4 & 1.36 & 63.7 & 1.33 & 25 \\
Pittstone & 7.5 & 30.1 & 3.66 & 84.3 & 1.07 & 25 \\
Goonyella & 7.7 & 26.1 & 3.38 & 71.8 & 1.05 & 20 \\
Akabira & 6.3 & 41.9 & 2.88 & 96.0 & 0.72 & 15 \\
\hline Blended coal & 8.2 & 26.8 & 2.20 & 79.0 & 1.15 & 100 \\
\hline
\end{tabular}

* Presented to the 102nd ISIJ Meeting, November 1981, S791 and S792, at Kyoto-fu Chusho Kigyo Kaikan in Kyoto. Manuscript received April 28, 1982. (C) 1983 ISIJ

** Hasaki Research Center, Central Research Laboratories, Sumitomo Metal Industries, Ltd., Hasaki-machi, Kashima-gun, Ibaraki 314-02. 
produced is divided into 10 divisions across the oven width and specimens for strength and other property measurements were obtained. Through this procedure, a large amount of coke with microscopically uniform quality can be obtained from the same charging coal at several carbonization temperatures and with several porosity values.

Temperature at each division was measured, as illustrated in Fig. 1, by inserting nine thermocouples into charging coal across the oven width. The specimens for the JIS drum index were obtained from the positions where temperature was measured.

\section{Measurements of Coke Properties and Their Procedures}

\section{Tensile strength}

Indirect measuring method of tensile strength (hereinafter referred to as tensile strength test) was used in this research. The method is generally used for rock mechanics and applied for the first time to coke by Patrick and Stacey) and Miyagawa and Fujishima. ${ }^{8)}$ Average of twenty measured data was considered as a representative value.

\section{Porosity}

Porosity was calculated from the apparent density given by the diameter, thickness and weight of a discshaped coke specimen, and the specific gravity measured for the ground specimen obtained after the tensile strength test according to JIS K2151.

\section{Micro-strength}

The specimen after the tensile strength test was used in the conventional micro-strength test after grinding between 14 and 28 mesh as well as the above specific gravity measurement. Sieve openings of 28, 48, 65 and 100 Tyler mesh were applied to evaluate the coke strength.

Above three tests were conducted on the specimens taken from ten divisions across the oven width. How-

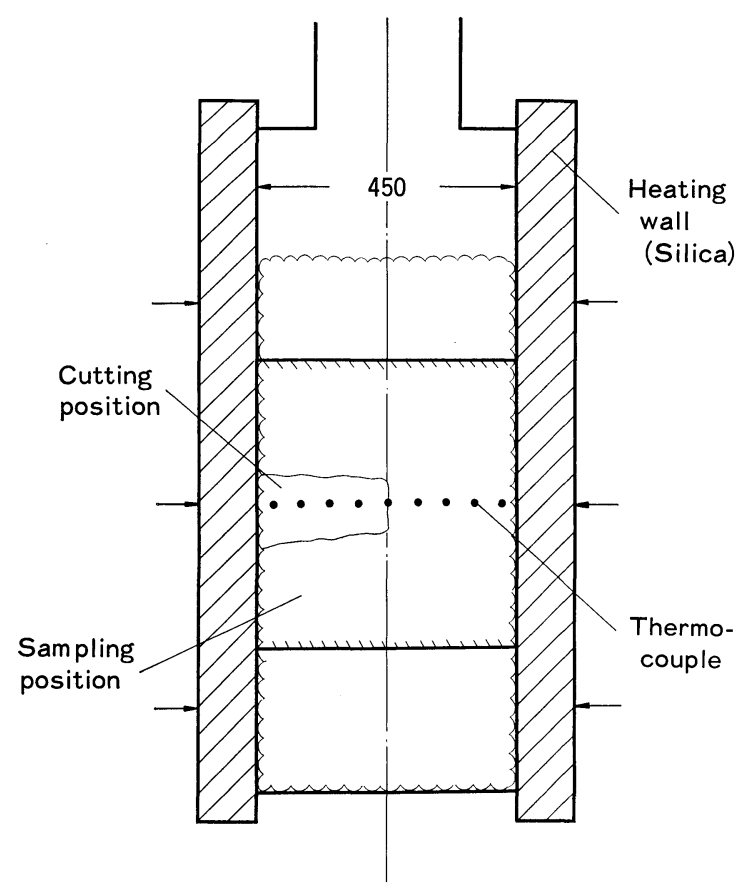

Fig. 1. Test coke oven and sampling position. ever, the JIS drum index test was conducted onto the coke taken from the central region of coke oven as shown in Fig. 1 according to JIS K2151.

\section{Test Results}

\section{Coke Property Variations across the Oven Width}

An example of the variations of the coke properties across the oven width is shown in Fig. 2. The results indicate that the coke near the oven wall has the higher apparent density and the higher strength than those near center, in agreement with other studies. ${ }^{10,11)}$ It is to be noticed, however, that the micro-strength decreases with the position from wall side to the center irrespective of porosity, while the variation of the tensile strength is related to that of the porosity.

It is considered that micro-strength is affected by the carbonization temperature, since this phenomenon is also observed in the coke produced under different conditions. ${ }^{12)}$ This suggests that micro-strength represents the inherent strength, since the higher degree of graphitization of carbon in coke is due to a higher carbonization temperature. This causes higher inherent strength within the normal carbonization temperature range. ${ }^{13,14)}$

\section{Inherent Strength of Coke}

Some tests have been performed to measure inherent strength of coke using micro-Vickers and/or Knoop hardness tester. ${ }^{15}$ ) Few reliable data on inherent strength is available because it lacks for the representativity of sample or the uniformity of coke structure. Therefore, the most preferable sieve opening for micro-strength to reflect coke inherent strength was surveyed in this research.

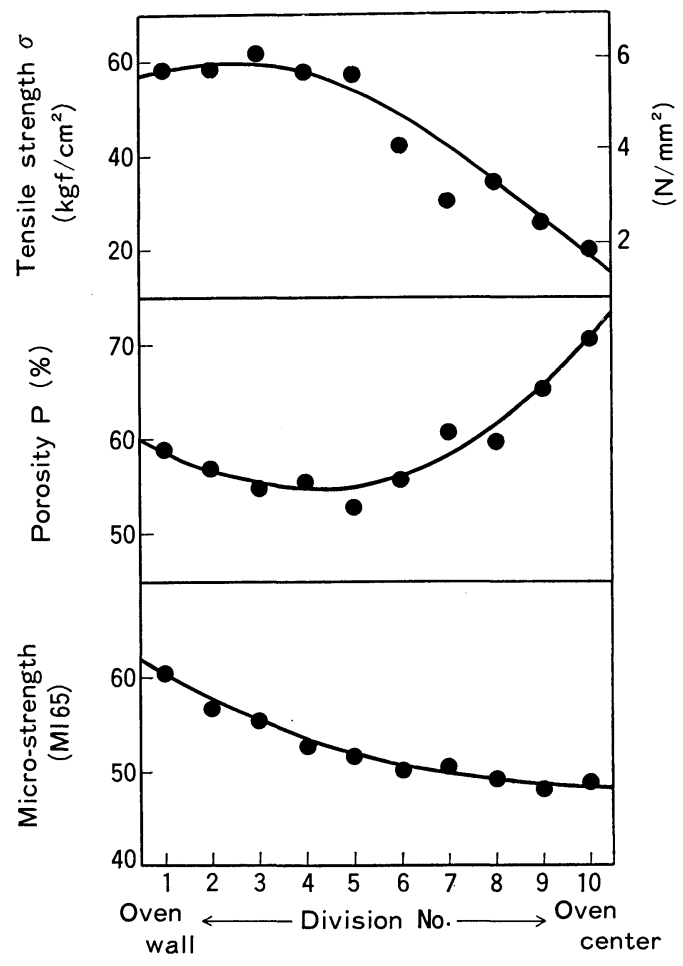

Fig. 2. Variation of coke properties across the oven width. 


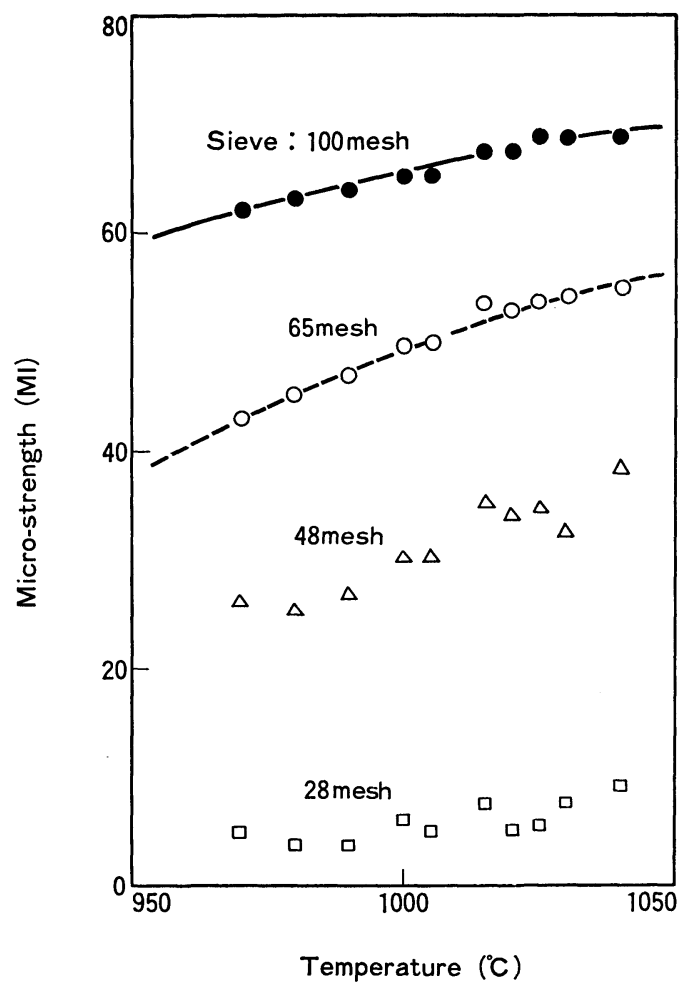

Fig. 3. Relation between micro-strength of coke and final carbonizing temperature.

The results described in Section III.1 is shown in Fig. 3 in which the relation between carbonization temperature and micro-strength with different sieve openings is shown. Better correspondence between carbonization temperature and micro-strength is obtained in the case of a smaller opening, which may evaluate inherent strength more correctly than the cases with wider ones. The results for the cases of 65 and 100 mesh openings show a clearer relation between the strength and temperature than with 28 and 48 mesh. This result suggests that the effect of pores and/or fine cracks on the measured data can be avoided by using a smaller opening.

\section{Porosity, Micro-strength and Tensile Strength}

Generally, the strength of porous material depends strongly on the porosity. Present results also show a rather good correlation between tensile strength and porosity, as illustrated in Fig. 4. A wide scattering is, however, still seen in Fig. 4, because the effect of inherent coke strength is not taken into account.

The micro-strength with 65 mesh $\left(M I_{65}\right)$ gives the inherent relative strength. It was used to group the data in Fig. 4. The results shown in Fig. 5 indicate that porosity and tensile strength have a close relation when the micro-strength is at the same level. This suggests that tensile strength of coke can be estimated by the porosity and the inherent strength, as in the cases of other conventional porous materials.

\section{Discussion}

\section{Tensile Strength}

Equation (1) has been proposed by Ryshkewitch ${ }^{16)}$

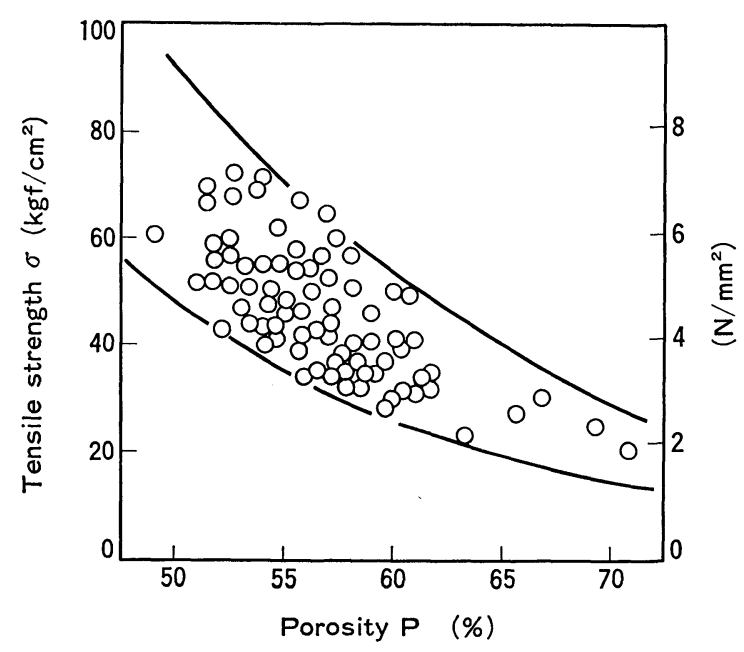

Fig. 4. Relation between porosity and tensile strength of various cokes.

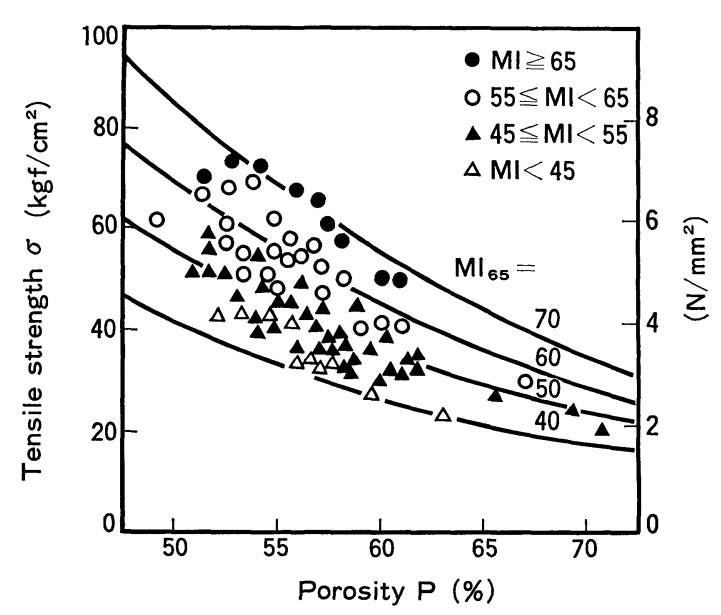

Fig. 5. Relation between porosity, micro-strength and tensile strength of various cokes.

and Knudsen ${ }^{17)}$ to express the strength of sintered ceramics, such as sintered alumina. For the estimation of tensile strength of coke, this seems to be the most suitable equation compared with others. The inherent strength $\sigma_{0}$ with linear regression equation of micro-strength $(M I)$ is substituted and all the data obtained in this work are analyzed. Equation (1) can be rewritten as Eq. (2) by applying the experimentally obtained constants;

$$
\sigma=\sigma_{0} \exp (-c P)
$$

where, $\sigma:$ tensile strength $\left(\mathrm{kgf} / \mathrm{cm}^{2}\right)$

$\sigma_{0}:$ inherent strength $\left(\mathrm{kgf} / \mathrm{cm}^{2}\right)$

$P$ : porosity (-)

$c$ : constant (-).

And the following equation was obtained,

$$
\begin{aligned}
& \sigma=(11.4 M I-114) \exp (-4.2 P) \\
& \text { with } \gamma=0.72, n=220,
\end{aligned}
$$

where, $M I$ : micro-strength with 65 mesh (\%)

$\gamma:$ correlation coefficient

$n$ : number of sample.

The tensile strength of coke from all the divisions 
was estimated using Eq. (2) with their porosity and micro-strength data, and the calculated values were compared with measured data. The results obtained from experiments for different bulk densities and carbonization temperatures are plotted in Figs. 6 and 7. They are in good agreement with the calculated values by Eq. (2) and the difference between the calculated and the measured values is small.

\section{Tensile Strength and JIS Drum Index}

Usually coke strength is expressed by the revolution strength such as the JIS drum index, the Micum index and the ASTM tumbler index for the purpose of quality control in the plant. Extensive researches on the index have been reported. ${ }^{18-23)}$ Very few reports are available which analyze the coke strength based on the inherent strength or discuss the relation with tumbler strength. In this report, the relation between the tensile strength for the theoretical research and the JIS drum index for quality control will be discussed.

1. Application of Rosin-Rammler's Particle Size Distribution Formula

It is well known that the coke size distribution after revolution test follows the Rosin-Rammler's formula ${ }^{22}$ ) given by

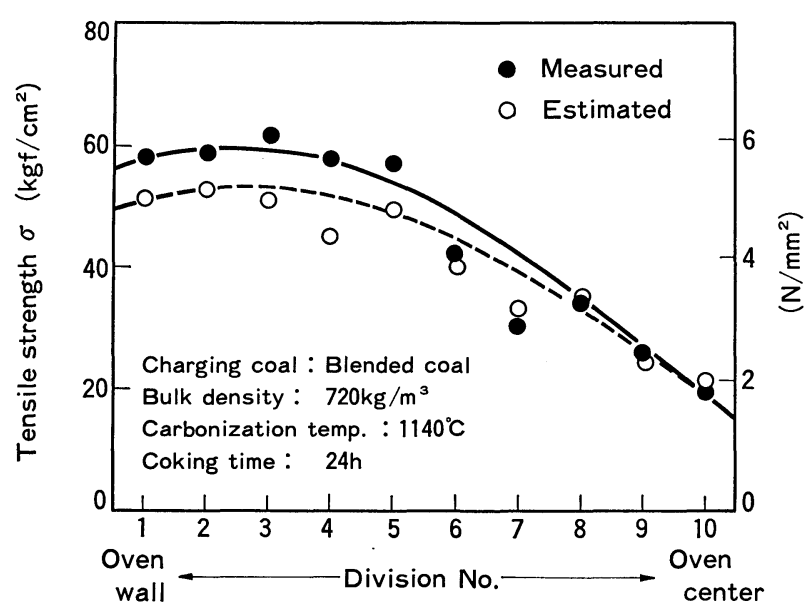

Fig. 6. Variation of tensile strength across the oven width.

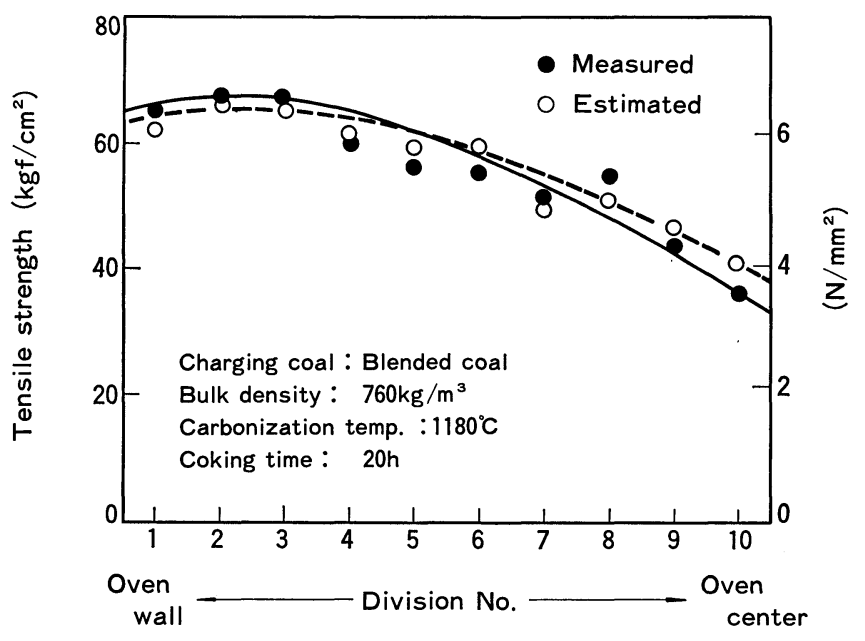

Fig. 7. Variation of tensile strength across the oven width.

$$
I_{x}=100 \exp \left(-b X^{m}\right)
$$

where, $I_{x}$ : cumulated grain ratio over the size of $X$ in the sample after grinding, in weight $(\%)$

$X: \quad$ grain size or sieve opening $(\mathrm{mm})$ $b, m:$ constants (-).

Taking logarithm of Eq. (3), we have

$$
R_{x}=b X^{m} \log (e)
$$

where, $R_{x}=2-\log \left(I_{x}\right)$

When the JIS drum index $D I_{x}$ is substituted in $I_{x}$ of Eq. (5), $R_{x}$ shows a very close relation with rotation number of the drum, as seen in Fig. 8, which is both for the conventional coke and for the formed coke. The $R$ values were calculated by Eq. (5) using $15 \mathrm{~mm}$ drum index $\left(D I_{15}\right)$ with increasing rotation number $Z$ for the conventional test method. For both cokes, the correlation is quite clear. The slope of the line in the figure depends, as previously suggested, ${ }^{19)}$ on the anti-breakage of coke, indicating that $R_{x}$ is an index determined by the breaking energy and inherent coke strength when $X$ is a constant.

The parameter relating the breaking energy and inherent coke strength is the constant $b$, since the constant $m$ in Eq. (4) is generally within a narrow range of 0.8 to 1.3. Furthermore, if $X$ and the breaking energy are constant, $b$ must be proportional to the inherent coke index.

The measured tensile strength $\sigma$ of several kind of coke has been found to have a close relation with drum index $\left(D I_{15}^{30}\right)$ as shown in Fig. 9. Therefore, Eq. (3) can be modified as follows:

$$
D I_{x}=100 \exp \left(-d \sigma^{-n} X^{m}\right)
$$

where, $\quad \sigma:$ tensile strength $\left(\mathrm{kgf} / \mathrm{cm}^{2}\right)$ $d, n:$ constants.

If $X^{m}$ is constant, Eq. (6) can be expressed as follows:

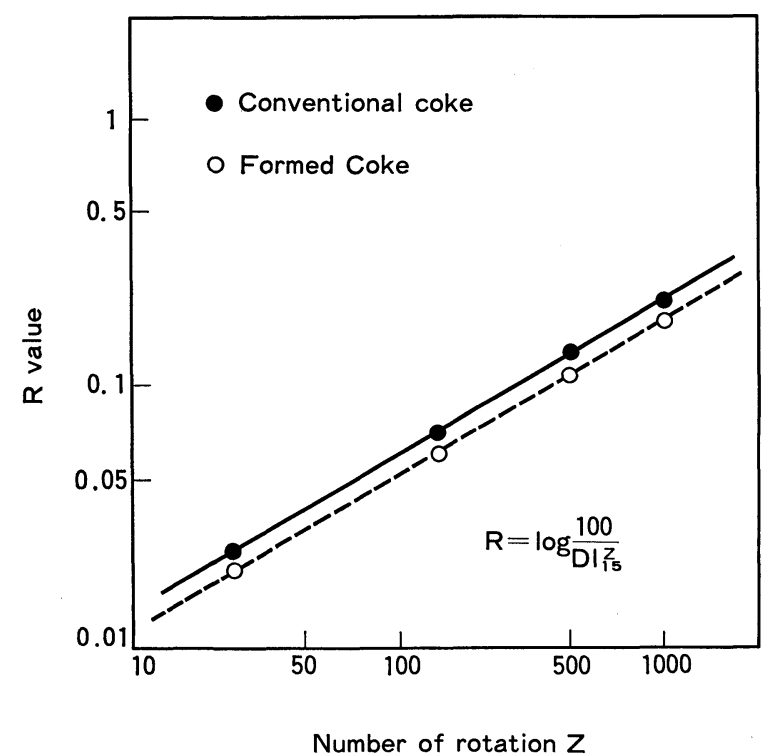

Fig. 8. Relation between $R$ value and number of rotation of different cokes. 


$$
D I=100 \exp \left(-k \sigma^{-n}\right)
$$

where, $k$ : constant.

By analyzing the data in Fig. 9 by Eq. (7), $k$ and $n$ are determined and the following equation can be obtained;

$$
D I_{15}^{30}=100 \exp \left(-0.81 \sigma^{-0.60}\right) ; \quad r=0.80
$$

Substituting $\sigma$ expressed by Eq. (2) into Eq. (8), JIS drum index can be estimated from porosity and micro-strength as follows:

$$
\begin{aligned}
D I_{15}^{30}= & 100 \exp [-0.81\{(11.4 M I \\
& \left.-114) \exp (-4.2 P)\}^{-0.60}\right] .
\end{aligned}
$$

The above concept may also be applied to other revolution indices, except those like $D I_{50}$ or $M_{40}$ which are affected strongly by structual defects in coke such as macro-cracks.

\section{Estimation of JIS Drum Index Distribution across the Oven Width}

Although the actual measurement of drum index across the oven width is impossible, the drum index distribution can be easily estimated by Eq. (6). Using the measured porosity and micro-strength data across the oven width given in Section III.1, the drum index distribution was estimated by Eq. (9) for 2 cases of different bulk densities of the charging coal.

The obtained drum index varies significantly between wall side and center part, as illustrated in Figs. 10 and 11 . Weighted average of drum index through the oven width was calculated by Eq. (10) and compared with the measured drum index, which is indicated by the thin line in Figs. 10 and 11. This comparison indicates that Eq. (9) accurately estimates the drum index.

$$
\overline{D I}=\sum_{i=1}^{n} D I_{i} W_{i} / W_{o}
$$

where, $\overline{D I}:$ weighted average of drum index

$D I_{i}:$ drum index at division $i$

$W_{i}$ : coke weight in division $i(\mathrm{~g})$

$W_{o}$ : sum of coke weight in divisions 1 to $n$ (g).

It can be concluded that the drum index for the control of industrial operation can be mostly estimated by porosity and micro-strength of coke through tensile strength. However, more discussions may be necessary since the effect of porosity distribution and micro-cracks has not been evaluated.

\section{Conclusions}

Coke strength has been studied considering that coke is a porous material. The following results have been obtained.

(1) Relative evaluation of inherent strength of coke can be given by the micro-strength index with a finer sieve opening.

(2) Tensile strength is estimated from porosity and micro-strength, and JIS drum index conventionally employed for control of operation is also estimated from those through tensile strength.

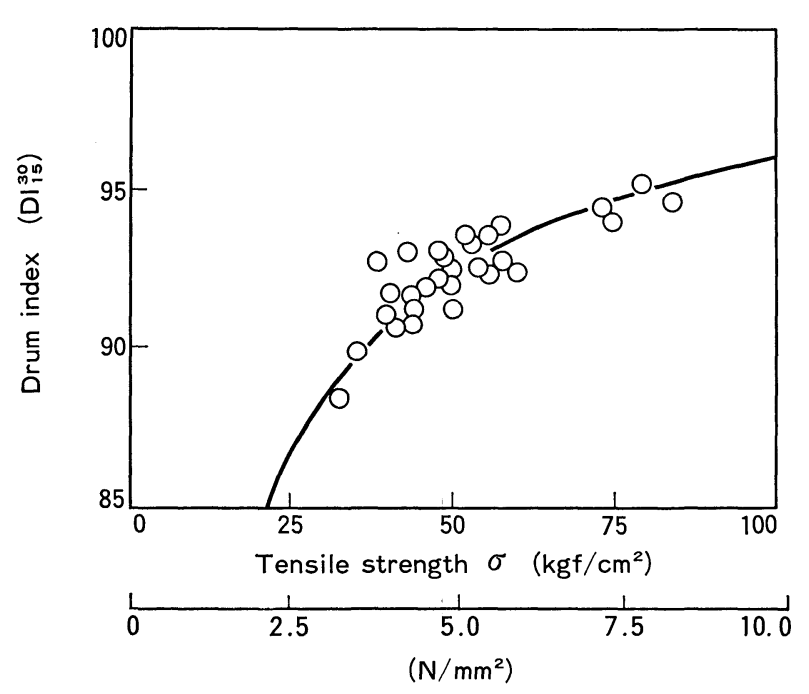

Fig. 9. Relation between tensile strength and JIS drum index $\left(D I_{15}^{30}\right)$ of various cokes.

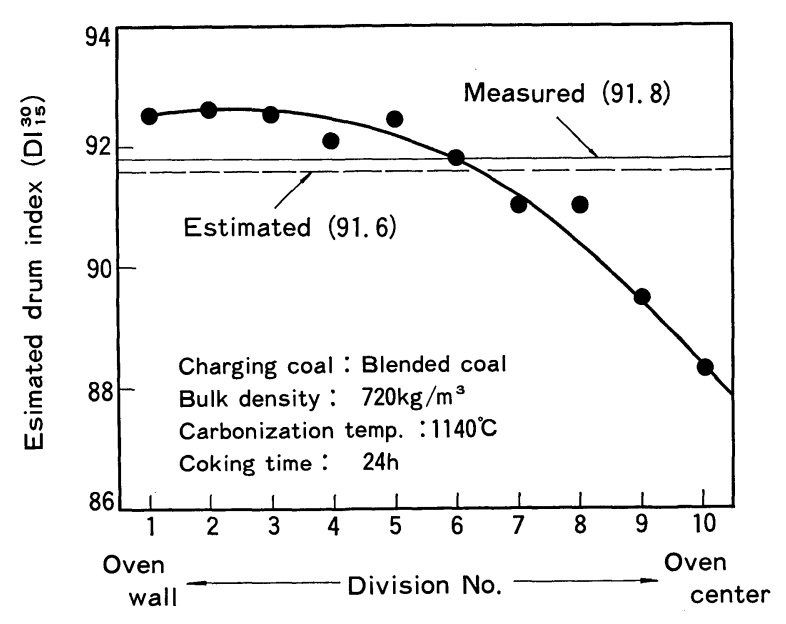

Fig. 10. Variation of estimated JIS drum index across the oven width.

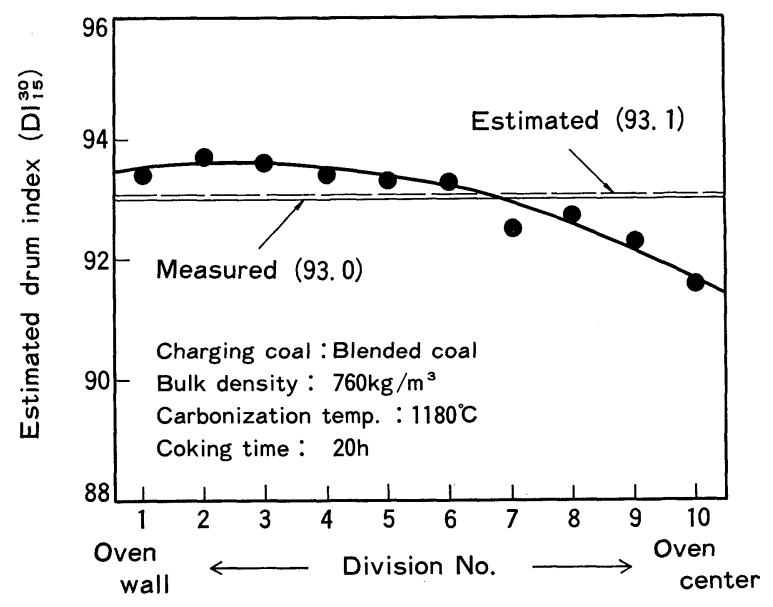

Fig. 11. Variation of estimated JIS drum index across the oven width.

In this study, a coke block produced in a test coke oven was sliced into 10 divisions and the coke sample from each division was analyzed to obtain these results.

The results show that the coke strength is deter- 
mined by the strength of porous material which depends on porosity and inherent strength. The more accurate relationship between drum index and coke properties may be obtained when the effects of pore distribution and micro-cracks are clarified.

\section{REFERENCES}

1) K. Nishioka and S. Yoshida: Trans. ISIJ, 23 (1983), 381.

2) Y. Yoshida: Annual Report of Coke Technology, Coke Series 4, The Fuel Soc. Japan, (1954), 67.

3) Y. Yoshida, K. Yamaguchi and K. Nagata: Annual Report of Coke Technology, Coke Series 4, The Fuel Soc. Japan, (1954), 81.

4) Yu. Ya. Filonenko, I. A. Pyzhenkov, V. N. Shapirov, G. N. Makarov and I. M. Dorofeev: Coke and Chem., (1975), No. 2, 15 .

5) H. Suginobe and T. Miyagawa: Coke Circular, Japan, 29 (1980), 159.

6) J. W. Patrick and A. E. Stacey: Fuel, 51 (1972), 81, 174, 206; 52 (1973), 27; and 54 (1975), 213, 256.

7) BCRA: Carbonization Research Report, 73 (1979).

8) T. Miyagawa and I. Fujishima: J. Fuel Soc. Japan, 54 (1975), 587; 55 (1976), 30.

9) M. Isobe, Y. Suzuki, M. Tate and H. Kitagawa: Tetsu-to-
Hagané, 66 (1980), 307.

10) E. M. Taits: Coke and Chem., (1963), No. 8, 31.

11) T. Miyazu, T. Fukuyama, K. Moriyama and T. Mori: Nippon Kokan Technical Report, (1967), No. 41, 139.

12) H. Joh, T. Nishi and H. Nakama: J. Fuel Soc. Japan, 46 (1967), 582.

13) T. Fukuyama, T. Miyazu, Y. Okuyama, H. Kimura and M. Shiraishi: J. Fuel Soc. Japan, 47 (1968), 607.

14) Y. Sunami, K. Nishioka, Y. Iwanaga, M. Ogawa and N. Oshiguri: Tetsu-to-Hagané, 66 (1980), A20.

15) M. Shiraishi, J. Kumai, H. Kimura and Y. Yoshida: J. Fuel Soc. Japan, 46 (1967), 483; 47 (1968), 695.

16) E. Ryshkewitch: J. Amer. Ceram. Soc., 36 (1953), 65.

17) F. P. Knudsen: J. Amer. Ceram. Soc., 42 (1959), 376.

18) H. Joh, S. Ida and Y. Miura: Coke Circular, Japan, 9 (1960), 67.

19) K. Nagata: Annual Report of Coke Technology, Coke Series 5, The Fuel Soc. Japan, (1956), 104.

20) A. Wasa and T. Nakai: Coke Circular, Japan, 19 (1970), 120.

21) T. Miyazu, T. Fukuyama and T. Koizumi: Nippon Kokan Technical Report, (1970), No. 48, 9.

22) K. Izutsu, K. Nomura, K. Mishina, K. Toda and K. Harada: Coke Circular, Japan, 24 (1975), 182.

23) M. Ota and H. Oiwa: J. Fuel Soc. Japan, 50 (1971), 634. 